of the gallocatechins, a condensation takes place between the pyrogallol groups of two separate molecules.

Gallic acid and pyrogallol will not condense to form purpurogallincarboxylic acid unless both substances are oxidized, and this suggests that in the gallocatechin series tho condensation takes place between two oxidized molecules. This is supported by the results of a study of the conditions required for the formation of purpurogallin.

The oxidations of (-)-epigallocatechin and its gallate are followed by a linkage of two molecules of the resultant $o$-quinones to form the $o$-quinone of a bisflavanol with the two pyrogallol groups joined by a C-C linkage. Further condensations of this type are excluded on steric grounds, and it is suggested that the primary condensation products undergo either oxidation or reduction. Reduction leads to the formation of one of three possible bisflavanols, whereas oxidation, if a galloyl group is present, could lead to the formation of one of two purpurogallin derivatives. The available evidence supports the view that the theaflavins of black tea have these structures.

Prof. K. Freudenberg (Heidelberg) said that the term leucoanthocyani(di)n was a misnomer for those naturally occuring substances which on treatment with hot mineral acid either under aerobic or anaerobic conditions yield anthocyanidins. He proposed that they be named either 'pre- or pro-anthocyanins'.

Dr. T. Swain (Low Temperature Research Station, Cambridge), in introducing his paper on "Methods for the Investigation of Complex Leucoanthocyanins", also referred to the confusion in the nomenclature of leucoanthocyanins. He suggested that leucoanthocyanins of known structure be called by their systematic name, whereas polymers and co-polymers of hydroxyflavans ('flavols') be known as 'flavolans'. 'Those flavolans which yielded anthocyanidins on treatment with hot mineral acid would be known as 'flavylogens'. Dr. Swain then described methods for separating polymeric leucoanthocyanins into size groups and for analysis of their end groups.

Mr. W. E. Hillis (Division of Forest Products, Commonwealth Scientific and Industrial Research Organization, Australia), in his paper on the formation of condensed tannins in plants (read by Dr. E. C. Bate-Smith), recalled the probable role of shikimic acid and related alicyclic acids in the biosynthesis of polyphenols. Shikimic acid is present in appreciable quantities in the actively proliferating cambium of eucalypts. A linear relation exists between the amounts of shikimic acid and the weights of enlarging leaves of young Eucalyptus sieberiana trees, but this relationship does not hold for the fully-grown leaf; later the amount of shikimic acid in mature leaves diminishes with age. The final stages of the biosynthesis of shikimic acid ean occur in the dark, and therefore shikimic acid present elsewhere in the tree need not necessarily originate in the leaves. The distribution of shikimic acid in leaves differs from that of the soluble polyphenols.

Comparative studies of the polyphenols in the cambium, sapwood and heartwood of three Eucalyptus species revealed the samo general pattern of polyphenols, but shikimic acid was absent from the heartwood and only traces occurred in the developing sapwood. Catechin was less in the heartwood, whereas ellagic and gallic acids increased. On the basis of these facts a possible scheme for the biosynthesis of the heartwood polyphenols was outlined.

Mr. Hillis recalled that he had previously suggested (Society of Leather Trades Chemists Symposium on Vegetable Tannins, 1956, p. 127) that as certain tannins contain appreciable amounts of polymeric leucoanthocyanins, monomeric forms, originating in the leaves, could be the precursors of these substances. Present information, however, favours the formation of heartwood leucoanthocyanins in situ. Adaptation of the leucoanthocyanin reaction has enabled the distribution of leucoanthocyanins in plant tissues to be studied by moans of coloured photomicrographs.

In dealing with flavans of the resoreinol series in relation to the chemistry of commercially important condensed tannins, Dr. D. G. Roux (Leather Industries Research Institute, Grahamstown, South Africa) said that an examination of previous work on wattle and quebracho extracts indicated that no direct evidence had been provided for the occurrence of catechins or flavan-3:4-diols as basic units in the corresponding tannins. The stereochemistry of the recently isolated black wattle catechin ( - ). $3: 7: 3^{\prime}: 4^{\prime}: 5^{\prime}$-pentahydroxyflavan and $(-)-7: 3^{\prime}$ : $4^{\prime}$-trihydroxyflavan-3:4-diol of quebracho heartwood was discussed. The progress of condensation of these compounds in the wood was examined by anthocyanidin formation, by number average molecular weights and by tannin analyses on radial and vertical drillings. These methods afford possible biochemical evidence of the presence of leucoanthocyanidins as intact flavan-3:4-diol units in these condensed tannins. The mode of cross-linkage in these condensed tannins must allow for its labile nature.

The chairman encouraged a vigorous discussion at the end of each paper, and among those participating were Drs. White and King (Forestal Central Laboratories), Bate-Smith, Thompson and Whalley. J. W. T. Seakins

\title{
BAMBOOS AND NUTMEGS
}

T WO important taxonomie studies have recently been published in The Gardens' Bulletin (Singapore, 16, 1958), namely, "Bamboos of Malaya" by R. E. Holttum, and "A Revision of the Malayan Myristicaceae" by J. Sinclair.

Holttum has pointed out that the classification of the bamboos, as of other Gramineae, is based on inflorescence, flower and fruit characters ; and in so far as such work tends to be done in herbaria, remote from the tropical collecting grounds, much information that would be of great use to the field botanist fails to be included. In fact, what the field botanist mostly sees are bamboos not in flower. Hence the value of vegetative characters, in particular the culm-sheaths, in field observations. This, indeed, is the kind of information possessed by the Malays, by whom the many kinds of bamboo are put to manifold domestic and other uses. Accordingly, in the present very full and informative work, classifications based on both vegetative and reproductive characters are given, 
together with many excellent line drawings. Botanists and foresters will note with interest an observation on the flowering of bamboos in Malaya. In the equable climate which prevails there, the simultaneous, gregarious flowering of single species in particular areas, sometimes at intervals of several years, which is a well-known phenomenon in India, apparently does not occur. On the contrary, the native Malayan species can continue to grow indefinitely, flower sporadically from time to time, or in some instances, flowering a little almost continuously ; the gregarious dying-back after a heavy flowering, as in India, is at most only an occasional feature of the Malayan scene. Among others, an item of considerable interest is a close analysis and comparison of the inflorescences in bamboos and grasses.
In revising the Myristicaceae, Sinclair has pointed out that a regional flora of this group, as, indeed, of any other group, is likely to be unsatisfactory unless it is seen against the considerably wider background of the species present in the whole of the adjacent Malaysian region. Thus, many species formerly considered to be confined to Malaya are now known to occur in Sumatra and Borneo. The difficulties encountered in the systematic treatment of the group are discussed. In the present revision, 53 species, 5 varieties and 1 form are described, whereas, in Ridley's "Flora", the equivalent numbers were 45 species and 4 varieties. Six new species are described. The text is well illustrated with line drawings and with photographs showing bark characters.

\title{
AMERICAN ARACHNIDA
}

$\mathrm{T}$ HE spider family Dictynidæ has only recently been separated from the allied Amaurobiidæ, and its North American species are here revised and described. It is a family of world-wide distribution, with more than thirty genera and three hundred species, predominantly found in the north temperate zone. A dozen are British.

The spiders themselves are small spinners of cribellate webs in a variety of situations, and are unusual in that many species are gregarious, living together in very large numbers. In some areas in the States their thick communal webs choke ornamental conifers and evergreens and so give the spiders an economic importance. Their general habits and mode of life are but little known, and of their courtship and mating even less has been described. As a whole they seem to belong to the spring and summer, at which season alone males are to be found. The females lay only a few eggs, enclosed in lenticular cocoons, which are hung in the webs.

A recent paper by Prof. R. V. Chamberlin and W. J. Gertsch* describes eight American genera and 159 species, 119 of which are placed in the genus Dictyna. All these are fully described with the close attention to detail that modern arachnology requires, and distribution maps are added for many of the commonest species. The paper ends with 47 plates, carrying more than 600 admirable drawings, the work

* Bulletin of the American Museum of Natural History. Vol. 116, Article 1 : The Spider Family Dietynidae in America North of Mexico. By Prof. Ralph V. Chamberlin and Willis J. Gertsch. Pp. 1-152+ plates 1-47. (New York: American Museum of Natural History, 1958.) 3.50 dollars. of Miss Marjorie Statham, whose artistry has enriched so many recent publications from the American Museum of Natural History.

It is obvious that this is one of the most painstaking revisions of a family of spiders that has appeared in recent years, and the authors must be congratulated on their achievement. At the same time its true significance can be properly judged only if two other points are mentioned. The first is that the authors themselves describe the revision as "still in many ways a preliminary one", since very large collections of Dictynidx are now held both in New York and Utah. Here is an indication of the amount of systematic work which even a single family of spiders may involve.

The second point is that this paper recalls others, comparable if not quite so large, lately published in the Bulletin of the American Museum of Natural History. Dr. Levi's revision of the genus Enoplognatha and Dr. Muma's survey of American Solpugida are conspicuous examples. These have been supplemented by the smaller but no less desirable publications in the lively series, now some two thousand in number, called American Museum Novitates. No fewor than twenty-six of these, all dealing with the systematic side of arachnology, have come into my laboratory during the past few years. Obviously, there is a vigorous and fertile school of arachnology in America, which is taking its share, and more, in the very considerable task of ordering the Arachnida of the world in a coherent, reliable and accurate system. THEODORE SAvORY

\section{OXYGEN AS A PREREQUISITE TO THE ORIGIN OF THE METAZOA}

\author{
By Dr. J. R. NURSALL
}

Department of Zoology, University of Alberta, Edmonton, Alberta

$\mathrm{D}^{2}$ URING recent years there has been a revival of interest in the problems of the origin of life. This has led to speculation and experimentation, mostly along biochemical and biophysical lines. Less attention has been focused on the problems of the next steps in organic evolution, namely, those attending the diversification of primitive living forms into the kingdoms of organisms recognized to-day.

One of the important questions concerns the sudden appearance of highly organized metazoans in the fossil record. To state this more specifically : Why are there no fossil records of animal life from earlier 